\title{
Palliative care and end-of-life measure outcomes: Experience of a tertiary care institute from South India
}

\author{
Praveen Adusumilli, Lingaraj Nayak, Vidya Viswanath', Leela Digumarti², Raghunadha Rao Digumarti
}

\begin{abstract}
Introduction: Desisting from disease directed treatment in the past weeks of life is a quality criterion in oncology service. Patients with advanced cancer have unrealistic expectations from chemotherapy and hold on to it as a great source of hope. Many oncologists continue futile and unnecessary treatments, instead of conveying to the patients the lack of benefit, resulting in delayed referral for palliative care (PC). Materials and Methods: This is a retrospective analysis of case records from June 2014 to December 20I5. The primary objective was to study, how far back in time terminally ill cancer patients received definitive cancer directed therapy (DCDT).Apart from patient demographics, the diagnosis, stage, and details of DCDT, and death were captured. PC referral data were recorded. DCDT to death was taken as treatment-free interval (TFI). Analysis was performed using IBM SPSS Statistics for Windows, Version 20. Results: A total of 292 case records were evaluated. Seventy-three had inadequate treatment details. Hence, 219 records were analyzed. PC referral was done in $78.5 \%$ of patients. Only best supportive care (BSC) without any DCDT was given in 27 patients. The most common reason for BSC was a poor performance status in $92.5 \%$. The median time from PC referral till death was 43.5 days (range: I-5I 8 days). Chemotherapy was the most common DCDT in $52.9 \%$ of patients. The median time from DCDT and death was 49 days (range: $0-359$ days). Cervical and ovarian cancers patients had the longest TFI ; shortest in unknown primary. Most patients died at home (70.4\%). Patients receiving PC preferred home or hospice as place of death. Of the 80 patients given hospice care, 39 (36.5\%) died in the hospice. Conclusion: While DCDT needs to be started at the right time, it should also be discontinued when futile. Early involvement of the PC team, even while patients are on DCDT makes the transition smoother and more meaningful.
\end{abstract}

Key words: End-of-Life measures, palliative care, South India, tertiary institute

\section{Introduction}

Palliative care (PC) is patient and family centered care that optimizes quality of life (QOL) by anticipating, preventing, and treating suffering. PC throughout the continuum of illness involves addressing physical, intellectual, emotional, social, and spiritual needs and to facilitate patient autonomy, access to information, and choice. ${ }^{[1]} \mathrm{PC}$ is considered a human right to health. ${ }^{[2]}$ Each year, while an estimated 40 million people are in need of PC, $78 \%$ of them live in low- and middle-income countries. Indeed, $98 \%$ of children needing PC live in low- and middle-income countries. ${ }^{[3]}$

India has a high load of cancer and it is rising. In 2015, the incidence of cancer in the country was estimated to be $1,148,691$, which is likely to go up to $1,320,928$ cases by the year $2020 .{ }^{[4,5]}$ A number of major barriers exist in the efforts to meet the needs for PC, such as national health policies, health-care systems which do not often include PC services and training on PC for health professionals. ${ }^{[6,7]}$ Even though the concept of PC exists for many decades, it has come in to limelight again after the advent of 2012 American Society of Clinical Oncology provisional clinical opinion on the integration of PC in to standard oncology care and transition the content in to a guideline. ${ }^{[8]}$ Early PC referral in an outpatient setting provides room for longer therapeutic relationship, discussion of goals of care, and advanced care planning, which could facilitate improved end-of-life (EOL) care outcomes. ${ }^{[9]}$

Desisting from disease directed treatment in the past weeks of life is a quality criteria of oncology service. Many oncologists choose to continue futile and unnecessary treatments, instead of conveying the patients that there are no benefits to maintaining the anticancer treatment. ${ }^{[10]}$ Various retrospective studies have reported active treatment rates in the past 4 weeks of life

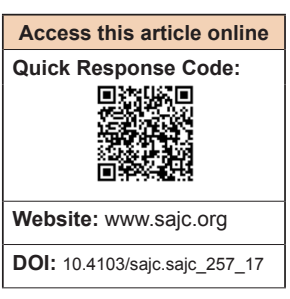

ranging from $23 \%$ to $55.6 \%{ }^{[11-14]}$ Patients with advanced cancer have unrealistic expectations regarding the treatment and hold on to chemotherapy as a great source of hope. ${ }^{[15-17]}$ Due to this a large proportion of $30 \%-50 \%$ patients die in the hospital, which is in about $25 \%$ of cases due to the harmful effects of chemotherapy which brings terminal cancer patients into such a state that they cannot be discharged from hospital. ${ }^{[18]}$ Furthermore, patients with metastatic cancer, who receive early PC, are most likely have better perception of their prognosis. This facilitates the understanding of the real benefits of new types of anticancer treatment. ${ }^{[19]}$

\section{Materials and Methods}

This is a retrospective analysis of case records from June 2014 to December 2015. The primary objective is to study, as a measure of PC, how far back in time did a terminally ill cancer patient receive definitive cancer directed therapy. The duration of such treatment was recorded in days/weeks/months.

Data were captured in a preformatted recording. Apart from patient demographics, the diagnosis, stage, and details of any Definitive Cancer Directed Treatment (DCDT), along with death were captured.

Data on referral to PC was recorded. The date of last definitive cancer directed treatment was used for calculate the treatment free interval (TFI) up to death as it was used as a measure of individual physicians futility of definitive treatment and utility of PC.

Palliative treatment like radiation to painful bony metastases and impending fracture were captured. Similarly, radiation for brain metastases with features of increased intra cranial pressure was taken as a life saving measure and not definitive treatment. Frequencies and percentages were calculated for overall descriptive statistics. To compare the improvement using

This is an open access journal, and articles are distributed under the terms of the Creative Commons Attribution-NonCommercial-ShareAlike 4.0 License, which allows others to remix, tweak, and build upon the work non-commercially, as long as appropriate credit is given and the new creations are licensed under the identical terms. and ${ }^{2}$ Gynaec Oncology, Homi Bhabha Cancer Hospital and Research Centre,Aganampudi, Andhra Pradesh, India

Correspondence to: Dr. Praveen Adusumilli, E-mail:praveen.adusumilli@yahoo.com
For reprints contact: reprints@ medknow.com

How to cite this article: Adusumilli P, Nayak L, Viswanath V, Digumarti L, Digumarti RR. Palliative care and end-of-life measure outcomes: Experience of a tertiary care institute from South India. South Asian J Cancer 2018;7:210-3. 
nominal data, Chi-square test was used. Analysis was performed using IBM Statistical Package for the Social Sciences version 20 (IBM Corp. Released 2011. IBM SPSS Statistics for Windows, Version 20.0. Armonk, NY: IBM Corp.).

\section{Results}

A total of 292 case records were evaluated. Seventy-three case records had inadequate treatment details. Hence, 219 case records were analyzed.

The baseline demographic and PC characteristics are depicted in Table 1. PC referral was done in $78.5 \%$ of patients. Only best supportive care (BSC) and no DCDT was given for 27 patients. The most common reason for BSC was poor performance status in $92.5 \%$ of patients. The median time from PC referral till death was 43.5 days (range: 1-518 days).

The last definitive treatment details are depicted in Table 2. Chemotherapy was the most common last definitive treatment given in $52.9 \%$ of patients. The median time from last definitive treatment given and death was 49 days (range: 0-359 days).

The incidence of various cancers and median TFI between last definitive treatment and death in various cancers according to the site of cancer is depicted in Table 3. Cervical and ovarian cancers patients had the longest TFI and patients with malignancy of undefined primary origin the shortest.

Most patients died at home $(70.4 \%)$. Patients receiving PC preferred home or hospice as place of death. Of the $80(36.5 \%)$ patients given hospice care, 39 died in the hospice.

\section{Discussion}

The availability of a PC Medicine Department in our institute, along with hospice and home care is perhaps the reason for early PC referrals (78\%).

Rugno et al. ${ }^{[20]}$ reported that patients who were not previously evaluated in PC received more chemotherapy in the past 6 weeks of life compared to those who had already been evaluated ( $40 \%$ vs. $5.9 \%, P=0.001)$ and survived longer (although statistically not significant). Temel et al. ${ }^{[21]}$ in a Phase III randomized controlled trial (RCT) of patients with newly diagnosed nonsmall cell lung cancer (NSCLC) compared early PC with standard care in an outpatient setting. Patients in the intervention arm had higher QOL, less aggressive EOL care, lower rates of depression and longer survival by 2.7 months.

The median TFI before death in our study of 49 days (range: 0-359 days), is more when compared to study by Braga et al.$^{[12]}$ A study from Earle et al. ${ }^{[22]}$ showed that the TFI before death varied from 65 to 71 days. Some characteristics predictive of an increase in the chances of a patient receiving chemotherapy in the past month of life are: a young woman, a chemo-responsive tumor and a small oncology service. ${ }^{[23]}$

The median time of 43.5 days (range: 1-518 days) between PC referral and death in our study is similar to that reported by Cheng et al. ${ }^{[24]}$ Time from PC consultation to death also decreased from 33 in 2003 to 11.5 days in 2008 over the 5 -year span in a study from Mayo Clinic. ${ }^{[25]}$ A delay in PC referral not only shortens the possibility for building rapport and providing meaningful relief of symptoms but also provides less opportunity for cost savings. Lowery et al. ${ }^{[26]}$ studied the cost saving benefit and health-care utilization in platinum
Table 1: Baseline characteristics

\begin{tabular}{lc}
\hline & $n(\%)$ \\
\hline Male & $107(48.9)$ \\
Female & $112(51.1)$ \\
Palliative care referral & $172(78.5)$ \\
No palliative care referral & $47(21.5)$ \\
Hospice admission & $79(36.1)$ \\
No hospice admission & $140(63.9)$ \\
Place of death & \\
Home & $154(70.4)$ \\
Hospital & $26(11.9)$ \\
Hospice & $39(17.8)$ \\
\hline
\end{tabular}

Table 2: Details of the last definitive treatment given

\begin{tabular}{lcc}
\hline & $n$ & Median TFI in days $(95 \%$ CI) \\
\hline Chemotherapy & 116 & $50(58-81)$ \\
Targeted therapy & 56 & $34(37-72)$ \\
Metronomic therapy & 14 & $30(25-72)$ \\
Radiotherapy & 5 & $58(28-97)$ \\
No treatment received & 28 & $53(47-114)$ \\
\hline
\end{tabular}

TFI=Treatment-free interval, $\mathrm{CI}=$ Confidence interval

Table 3: Median treatment-free interval according to disease site

\begin{tabular}{lcc}
\hline Disease site & $n$ & Median TFI in days $(\mathbf{9 5 \%}$ \\
\hline Head and neck & 30 & $69.5(55-128)$ \\
Breast & 29 & $29(28-62)$ \\
Lung & 26 & $44(35-67)$ \\
Cervix & 13 & $121(68-142)$ \\
Ovary & 6 & $92.5(8-187)$ \\
Colorectal & 15 & $52(38-80)$ \\
Pancreaticobiliary & 20 & $38(35-73)$ \\
Hepatocellular carcinoma & 9 & $30(4-86)$ \\
Gastric cancer & 25 & $55(45-94)$ \\
Renal cell carcinoma & 6 & $32(13-54)$ \\
Prostate cancer & 2 & $72(69-83)$ \\
Urinary bladder & 1 & - \\
Bone cancers & 6 & $34.5(25-82)$ \\
Acute leukemia & 2 & $60(16-104)$ \\
Chronic leukemia & 8 & $37.5(10-81)$ \\
Lymphoma & 8 & $30.5(11-90)$ \\
Pediatric cancers & 2 & $24.5(21-94)$ \\
Metastases of unknown origin & 2 & $19(6-44)$ \\
Miscellaneous & 9 & $108(57-124)$ \\
\hline TFI Treartec &
\end{tabular}

TFI=Treatment-free interval, $\mathrm{CI}=$ Confidence interval

resistant ovarian cancer. In this study, it was seen that early PC was associated with cost savings of $\$ 1285$ per patient over routine care. Temel et al. reported from an RCT in NSCLC that in patients receiving early specialist $\mathrm{PC}$ intervention, a higher proportion were aware that their disease was not curable at 12 weeks. Furthermore, patients in the early PC group had better awareness that the goal of cancer treatment was not cure. Patients who had better illness perception and better awareness of goals of treatment received less intravenous chemotherapy toward EOL. ${ }^{[27]}$ Various studies by Ghoshal et al. ${ }^{[28]}$ and McCaffrey et al. ${ }^{[29]}$ focused on the economic challenges of palliative and EOL care.

The ENABLE II study randomly assigned patients with advanced cancer to an advanced practice nursing PC 
intervention versus usual care. It found a higher QOL and lower depressed mood with the intervention. ${ }^{[30]}$ The ENABLE III study of Bakitas et al..$^{[31]}$ also compared early versus delayed $\mathrm{PC}$ in both solid tumors and hematological malignancies and concluded that there is improvement in QOL and 1 year survival without significant benefit in overall survival. The oncologists, nurses, and patients perspectives on integration of early specialist PC from India is studied by Salins et al. ${ }^{[32]}$

The last definitive treatment given in our study was chemotherapy in $53 \%$ of patients. Similar to our study, in a systematic review by Luta et al., ${ }^{[33]}$ chemotherapy is most frequently reported "life prolonging treatment" at EOL. A study by Rochidneux et al. ${ }^{[34]}$ stated $39 \%$ of patients with metastatic solid tumors received chemotherapy in the past 3 months of life.

Place of death is one of the quality markers for the care at EOL. ${ }^{[35]}$ Thirty-six percent of patients had hospice care at some point of time in their PC and $17 \%$ of patients died in the hospice. In a study by Mack et al. ${ }^{[36]}$ among adolescents and young adults, 23\% of patients were in hospice care before death, with the first enrolment at a median of 20 days (range: 8-45 days) before death. Similar to a study by Paris et al. ${ }^{[37]}$ most of our patients receiving PC died at home.

\section{Conclusion}

While the decision to implement DCDT in time is as important in cancer therapy, it is equally imperative to relinquish futile treatments for cancer while continuing PC. Early involvement of the PC team, even while patients are on DCDT makes the transition smoother, more meaningful and goal setting. The recognized lack of optimum prognostic tools and the acknowledged optimism of oncologists favor the institution of unnecessary "super-treatments." When receiving chemotherapy, patients with tumors with a low chance of responding to treatment and/or with borderline or inadequate functional performance will most likely experience an iatrogenic decrease in their life expectancy.

\section{Financial support and sponsorship}

Nil.

\section{Conflicts of interest}

There are no conflicts of interest.

\section{References}

1. Dahlin C, National Consensus Project for Quality Palliative Care. Clinical Practice Guidelines for Quality Palliative Care. Pittsburgh, PA: National Consensus Project; 2013.

2. World Health Organization. Palliative Care; 2015. Available from: http:// www.who.int/mediacentre/factsheets/fs402/en/. [Last accessed on 2016 Jul 03].

3. Rajagopal MR, Venkateswaran C. Palliative care in India: Successes and limitations. J Pain Palliat Care Pharmacother 2003; 17:121-8.

4. Goss PE, Strasser-Weippl K, Lee-Bychkovsky BL, Fan L, Li J, Chavarri-Guerra $Y$, et al. Challenges to effective cancer control in China, India, and Russia. Lancet Oncol 2014; 15:489-538.

5. Central Bureau of Health Intelligence. Projected Cases of Cancer at India Level for Selected Times and Selected Time Periods. Available from: http://www.cbhidghs.nic.in/writereaddata/mainlinkFile/NHP-2015. pdf. [Last accessed on 2017 Aug 07].

6. Tharappel E, Rajaram P. Barriers and challenges encountered by end-of-life care professionals: An Indian perspective. J Palliat Care 2014;30:200.

7. Joranson DE, Rajagopal MR, Gilson AM. Improving access to opioid analgesics for palliative care in India. J Pain Symptom Manage 2002;24:152-9.

8. Smith TJ, Temin S, Alesi ER, Abernethy AP, Balboni TA, Basch EM, et al. American Society of Clinical Oncology provisional clinical opinion: The integration of palliative care into standard oncology care. J Clin Oncol $2012 ; 30: 880-7$
9. Hui D, Bruera E. Integrating palliative care into the trajectory of cancer care. Nat Rev Clin Oncol 2016;13:159-71.

10. Bouleuc C, Chvetzoff G. End of chemotherapy decision for metastatic breast cancer patients. Bull Cancer 2009;96 Suppl 2:81-9.

11. Earle CC, Neville BA, Landrum MB, Souza JM, Weeks JC, Block SD, et al. Evaluating claims-based indicators of the intensity of end-of-life cancer care. Int J Qual Health Care 2005; 17:505-9.

12. Braga S, Miranda A, Fonseca R, Passos-Coelho JL, Fernandes A, Costa JD, et al. The aggressiveness of cancer care in the last three months of life: A retrospective single centre analysis. Psychooncology 2007; 16:863-8.

13. Näppä U, Lindqvist $\mathrm{O}$, Rasmussen BH, Axelsson B. Palliative chemotherapy during the last month of life. Ann Oncol 2011;22:2375-80.

14. Sanz Ortiz J. Chemotherapy at the end of life: Up until when? Clin Transl Oncol 2012;14:667-74.

15. Weeks JC, Catalano PJ, Cronin A, Finkelman MD, Mack JW, Keating NL, et al. Patients' expectations about effects of chemotherapy for advanced cancer. N Engl J Med 2012;367: 1616-25.

16. Chen AB, Cronin A, Weeks JC, Chrischilles EA, Malin J, Hayman JA, et al. Expectations about the effectiveness of radiation therapy among patients with incurable lung cancer. J Clin Oncol 2013;31:2730-5.

17. Grunfeld EA, Maher EJ, Browne S, Ward P, Young T, Vivat B, et al. Advanced breast cancer patients' perceptions of decision making for palliative chemotherapy. J Clin Oncol 2006;24:1090-8.

18. Martoni AA, Tanneberger S, Mutri V. Cancer chemotherapy near the end of life: The time has come to set guidelines for its appropriate use. Tumori 2007;93:417-22.

19. Temel JS, Greer JA, Admane S, Gallagher ER, Jackson VA, Lynch TJ, et al. Longitudinal perceptions of prognosis and goals of therapy in patients with metastatic non-small-cell lung cancer: Results of a randomized study of early palliative care. J Clin Oncol 2011;29:2319-26.

20. Rugno FC, Paiva BS, Paiva CE. Early integration of palliative care facilitates the discontinuation of anticancer treatment in women with advanced breast or gynecologic cancers. Gynecol Oncol 2014;135:249-54.

21. Temel JS, Greer JA, Muzikansky A, Gallagher ER, Admane S, Jackson VA, et al. Early palliative care for patients with metastatic non-small-cell lung cancer. N Engl J Med 2010;363:733-42.

22. Earle CC, Neville BA, Landrum MB, Ayanian JZ, Block SD, Weeks JC, et al. Trends in the aggressiveness of cancer care near the end of life. J Clin Oncol 2004;22:315-21.

23. Yun YH, Kwak M, Park SM, Kim S, Choi JS, Lim HY, et al. Chemotherapy use and associated factors among cancer patients near the end of life. Oncology 2007;72: 164-71.

24. Cheng WW, Willey J, Palmer JL, Zhang T, Bruera E. Interval between palliative care referral and death among patients treated at a comprehensive cancer center. J Palliat Med 2005;8:1025-32.

25. Kamal AH, Swetz KM, Carey EC, Cheville AL, Liu H, Ruegg SR, et al. Palliative care consultations in patients with cancer: A mayo clinic 5-year review. J Oncol Pract 2011;7:48-53.

26. Lowery WJ, Lowery AW, Barnett JC, Lopez-Acevedo M, Lee PS, Secord AA, et al. Cost-effectiveness of early palliative care intervention in recurrent platinum-resistant ovarian cancer. Gynecol Oncol 2013;130:426-30.

27. Temel JS, Greer JA, Admane S, Gallagher ER, Jackson VA, Lynch TJ, et al. Longitudinal perceptions of prognosis and goals of therapy in patients with metastatic non-small-cell lung cancer: Results of a randomized study of early palliative care. J Clin Oncol 2011;29:2319-26.

28. Ghoshal A, Damani A, Salins N, Deodhar J, Muckaden MA. Economics of palliative and end-of-life care in India: A Concept paper. Indian J Palliat Care 2017;23:456-61.

29. McCaffrey N, Cassel JB, Coast J. An economic view on the current state of the economics of palliative and end-of-life care. Palliat Med 2017;31:291-2.

30. Bakitas M, Lyons KD, Hegel MT, Balan S, Brokaw FC, Seville J, et al. Effects of a palliative care intervention on clinical outcomes in patients with advanced cancer: The project ENABLE II randomized controlled trial. JAMA 2009;302:741-9.

31. Bakitas MA, Tosteson TD, Li Z, Lyons KD, Hull JG, Li Z, et al. Early versus delayed initiation of concurrent palliative oncology care: Patient outcomes in the ENABLE III randomized controlled trial. J Clin Oncol 2015;33: 1438-45.

32. Salins N, Patra L, Usha Rani MR, Lohitashva SO, Rao R, Ramanjulu R, et al. Integration of early specialist palliative care in cancer care: Survey of oncologists, oncology nurses, and patients. Indian J Palliat Care 2016;22:258-65.

33. Luta X, Maessen M, Egger M, Stuck AE, Goodman D, Clough-Gorr KM, et al. Measuring intensity of end of life care: A systematic review. PLoS One 2015; 10:e0123764.

34. Rochigneux P, Raoul JL, Beaussant Y, Aubry R, Goldwasser F, South Asian Journal of Cancer Volume 7 Issue 3 July-September 2018 
Tournigand C, et al. Use of chemotherapy near the end of life: What factors matter? Ann Oncol 2017;28:809-17.

35. Pollockquestions K. Is home always the best and preferred place of death? bmj. 2015; 19.

36. Mack JW, Chen K, Boscoe FP, Gesten FC, Roohan PJ, Schymura MJ, et al.
High intensity of end-of-life care among adolescent and young adult cancer patients in the New York state medicaid program. Med Care 2015;53: 1018-26.

37. Paris J, Morrison RS. Evaluating the effects of inpatient palliative care consultations on subsequent hospice use and place of death in patients with advanced GI cancers. J Oncol Pract 2014;10:174-7. 